(A) CART3

Turtle-CART3 Xenopus-CART3 Zebrafish-CART3b Zebrafish-CART3a Tilapia-CART3a Tilapia-CART3b Takifugu-CART $3 a$ Taki fugu-CART $3 \mathrm{~b}$ Tetraodon-CART3a Tetraodon-CART3b Medaka-CART3a Medaka-CART3a Coelacanth-CART3 Chicken-C Chicken-CART1
Human-CART1

Turtle-CART3 Xenopus-CART 3 Zebrafish-CART3b Zebrafish-CART3a Tilapia-CART3a Tilapia-CART $3 b$ Takifugu-CART3 Takifu-CART3b Takifu Tetraodon-CART3b Medaka-CART3a Medaka-CART3b Coelacanth-CART 3 Chicken-CART1 Human-CART1

\title{
(B) CART4
}

Xenopus-CART Tilapia-CART 4 Tetraodon-CART4 Taki fugu-CART 4 Zebrafish-CART4 Elephant shark-CART4 Damselfish-CART4 Spotted gar-CART 4 Spotted gar-CART4
Coelacañth-CART4

Xenopus-CART Tilapia-CART 4 Tetraodon-CART4 Takifugu-CART 4 Zebrafish-CART4 Elephant shark-CART4 Damselfish-CART 4 Spotted gar-CART Coelacañth-CART4
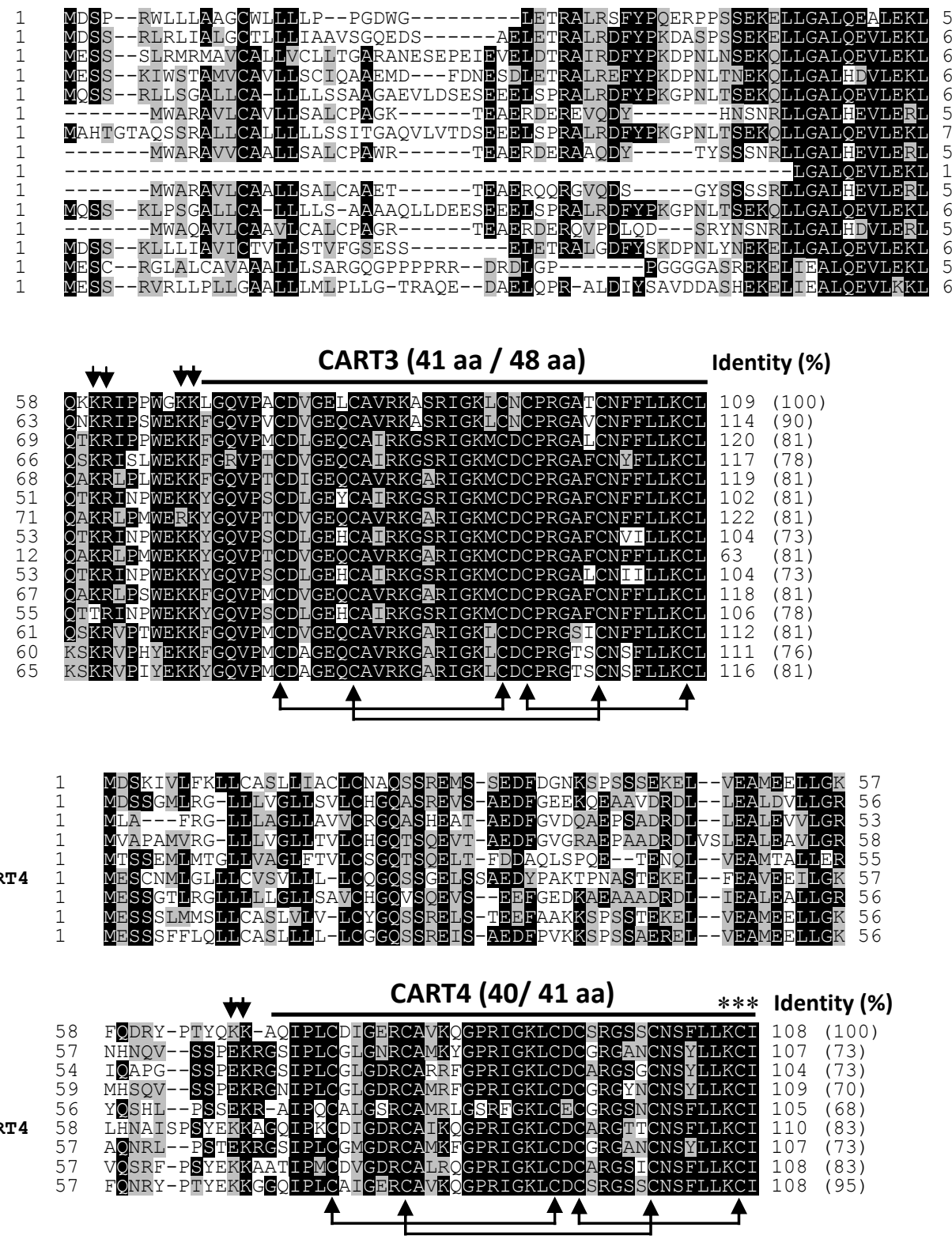

\section{S1 Fig}

